\title{
Human Anti-Chimeric Antibody Positive
}

National Cancer Institute

\section{Source}

National Cancer Institute. Human Anti-Chimeric Antibody Positive. NCI Thesaurus. Code C150631.

An indication that antibodies directed against chimeric therapeutic antibodies have been detected in a human sample. 